\section{Oral Nodular Lesions in Patients with Sjögren's Syndrome: Unusual Oral Implications of a Systemic Disorder}

\author{
Juliana Barchelli Pinheiro ${ }^{1}$, Camila Tirapelli ${ }^{1}$, Claudia Helena Lovato da Silva ${ }^{1}$, \\ Marilena Chinali Komesu², Flávio Calil Petean ${ }^{3}$, Paulo Louzada Junior ${ }^{3}$, Jorge \\ Esquiche León ${ }^{4}$, Ana Carolina Fragoso Motta ${ }^{4}$
}

Sjögren's syndrome (SS) is a systemic chronic autoimmune disorder affecting the lacrimal and salivary glands. SS may manifest as primary SS (pSS) or secondary SS (sSS), the latter occurring in the context of another autoimmune disorder. In both cases, the dry eyes and mouth affect the patient's quality of life. Late complications may include blindness, dental tissue destruction, oral candidiasis and lymphoma. This paper reports two cases of SS, each of them presenting unusual oral nodular lesion diagnosed as relapsed MALT lymphoma and mucocele. The importance of the diagnosis, treatment and management of the oral lesions by a dentist during the care of SS patients is emphasized, as the oral manifestations of SS may compromise the patient's quality of life.

\author{
'Department of Dental Material and \\ Prosthesis, School of Dentistry of \\ Ribeirão Preto, USP - Universidade de \\ São Paulo, Ribeirão Preto, SP, Brazil \\ ${ }^{2}$ Department of Morphology, \\ Physiology and Pathology, School \\ of Dentistry of Ribeirão Preto, \\ USP - Universidade de São Paulo, \\ Ribeirão Preto, SP, Brazil \\ ${ }^{3}$ Department of Internal Medicine, \\ Medical School of Ribeirão Preto, \\ USP - Universidade de São Paulo, \\ Ribeirão Preto, SP, Brazil \\ ${ }^{4}$ Department of Stomatology, Public \\ Oral Health and Forensic Dentistry, \\ School of Dentistry of Ribeirão \\ Preto, USP - Universidade de São \\ Paulo, Ribeirão Preto, SP, Brazil
}

\section{Correspondence: Ana Carolina Fragoso Motta, Avenida do Café s/n, Monte Alegre, 14090-904 Ribeirão Preto, SP, Brasil. Tel: +55-16-3315- 4067. e-mail: anacfm@usp.br \\ Key Words: Sjögren's syndrome, oral implications, dental treatment, mucocele, lymphoma.}

\section{Introduction}

Sjögren's syndrome (SS) is a systemic chronic autoimmune disorder characterized by lymphocytic infiltration of the exocrine glands, and oral and ocular dryness $(1,2)$. The disease is classified as primary SS (pSS) when it affects the salivary and lacrimal glands, causing ocular and oral dryness and as secondary SS (sSS) when it is associated with other rheumatic disease, such as systemic lupus erythematous, rheumatoid arthritis, among others (3). SS has been reported as one of the most prevalent autoimmune disorders, affecting between $0.5-3 \%$ of the adult population, especially women $(3,4)$.

The management of SS involves a large variety of dental and medical specialties, such as oral diagnosis, oral pathology, rheumatology, dermatology, ophthalmology, immunology, pneumology and gynecology, due to the great spectrum of manifestations, including the glandular and extraglandular manifestations (5). In late complications, 4\%-7\% of patients with SS develop B-cell lymphomas, among which $48 \%-75 \%$ are extranodal marginal zone B-cell lymphomas of mucosa-associated lymphoid tissue (MALT lymphoma), frequently located in the parotid gland. MALT lymphoma affecting the minor salivary glands in SS patients is rare $(6,7)$. It is interesting to note that, although obstructive phenomena by periductal lymphocytic infiltrates can be observed in minor salivary glands from SS patients, reactive lesions, such as oral mucocele, are uncommon (8).

There is considerable information in the medical literature regarding pathogenesis and related topics in the SS, including the most common oral complications, such as caries, periodontal diseases and candidiasis (9); however, clinicopathological findings focusing on how dentists can diagnose rare oral complications and also improve oral health in SS patients are scarce. Thus, in the present study was described and discussed the oral examination, diagnosis and treatment plan for two SS patients in order to help professionals from different areas to identify the usual and unusual oral manifestations of SS in its early stages and then to develop strategies for treating and controlling properly these patients.

\section{Case Report}

Case 1

A 35-year-old Brazilian woman was admitted to the Clinic for Special Needs Patients of the Dental School of Ribeirão Preto, Universidade de São Paulo, complaining of dry mouth and generalized dental hypersensitivity. The patient had a medical history of systemic erythematous lupus (SLE) diagnosed 9 years before, when she presented glomerulonephritis, SSS, arterial hypertension secondary to lupus nephritis, cerebrovascular accident (CVA) and MALT lymphoma involving the bilateral parotid and submandibular glands, which was treated with chemotherapy, showing remission upon initial treatment. In addition, she also had a history of osteoporosis. Her medical treatment consisted of $200 \mathrm{mg}$ carbamazepine every $8 \mathrm{~h}$, $100 \mathrm{mg}$ acetylsalicylic acid daily, $50 \mathrm{mg}$ atenolol daily, 5 
mg prednisone daily, $\mathrm{CaCO}_{3}$ plus vitamin D3 twice a day, $20 \mathrm{mg}$ omeprazole daily and $35 \mathrm{mg}$ risedronate weekly.

Upon physical examination, she presented gait impairment secondary to CVA and no swelling or other findings in the area of the parotid or submandibular glands. The oral physical examination revealed atrophic mucosa, thick and spumous saliva, gingivitis, generalized caries cavities, cracked restorations, dentoalveolar abscess and partial dental loss. In addition, the patient had a history of recurrent inflammation of the sublingual gland secondary to obstruction by calculus formation, which was controlled by gland drainage and calculus removal (Fig. 1). During one of her routine dental visits, 1 year after the diagnosis of MALT Iymphoma, was found an asymptomatic nodular lesion on the upper lip, which clinical diagnosis included benign neoplasm and reactive lesion.

The nodular lesion on the upper labial mucosa was
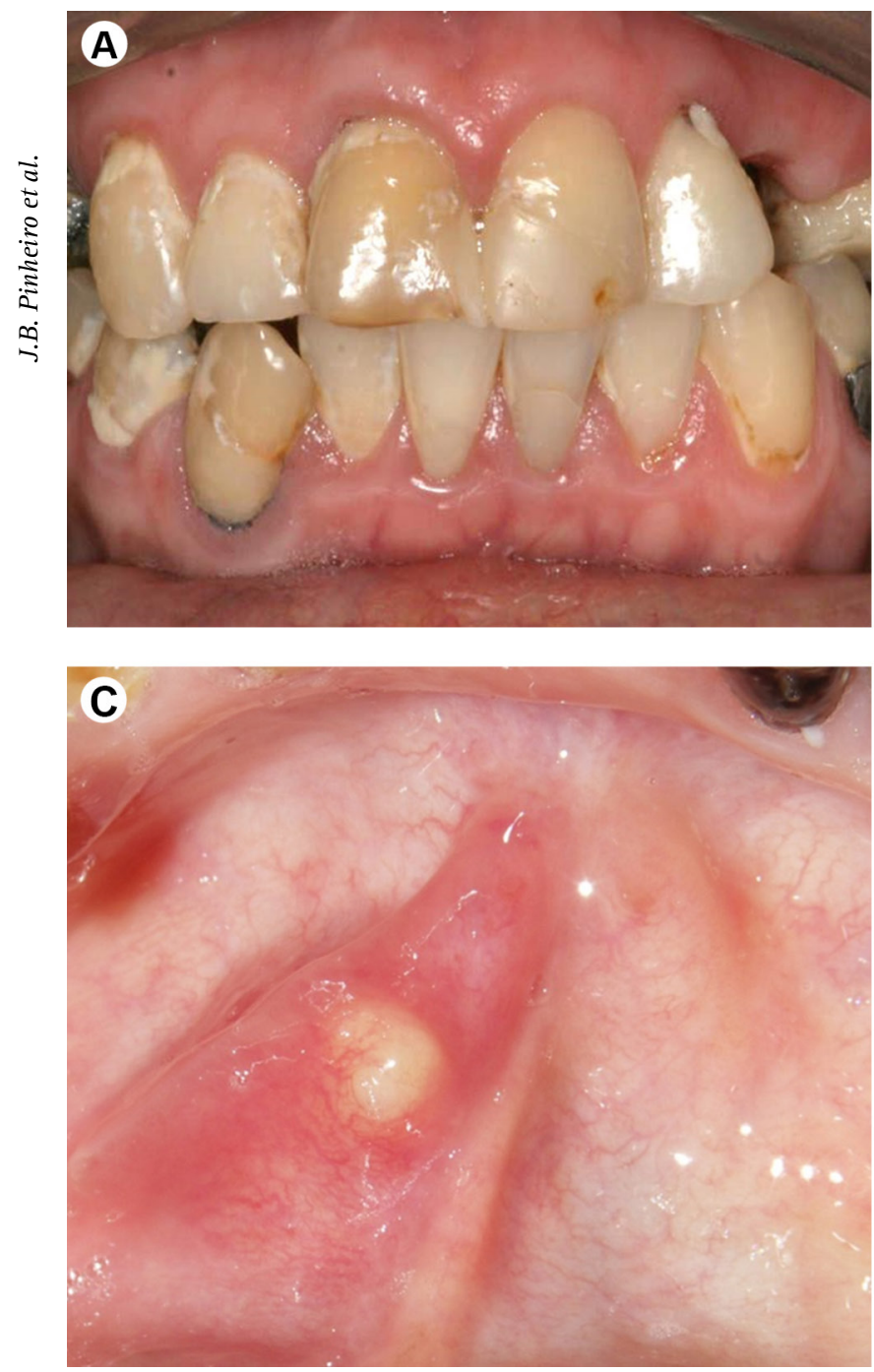

surgically removed and the microscopic analysis showed a nodular proliferation of atypical lymphoid cells containing lymphoepithelial lesions (LELs) and at the periphery was observed infiltration and destruction of glandular architecture. The residual minor salivary glands showed focal lymphocytic sialadenitis, usually in perivascular or periductal locations and adjacent to normal-appearing mucous acini (Fig. 2). Immunohistochemical (IHC) analysis showed numerous CD20-positive cells than CD3-positive cells was observed. CD138 evidenced scarce plasma cells. CD20 and CD43 showed similar immunostaining pattern, while CD10 was negative. The B-cell population did show kappa light chain restriction. Cell proliferation as assessed by the Ki-67 index was $<15 \%$ (Fig. 3). AE1/AE3 pan-cytokeratin highlighted the LELs. Based on the clinicopathological features, it was considered compatible with relapsed MALT Iymphoma. The patient was referred to a hematologist for
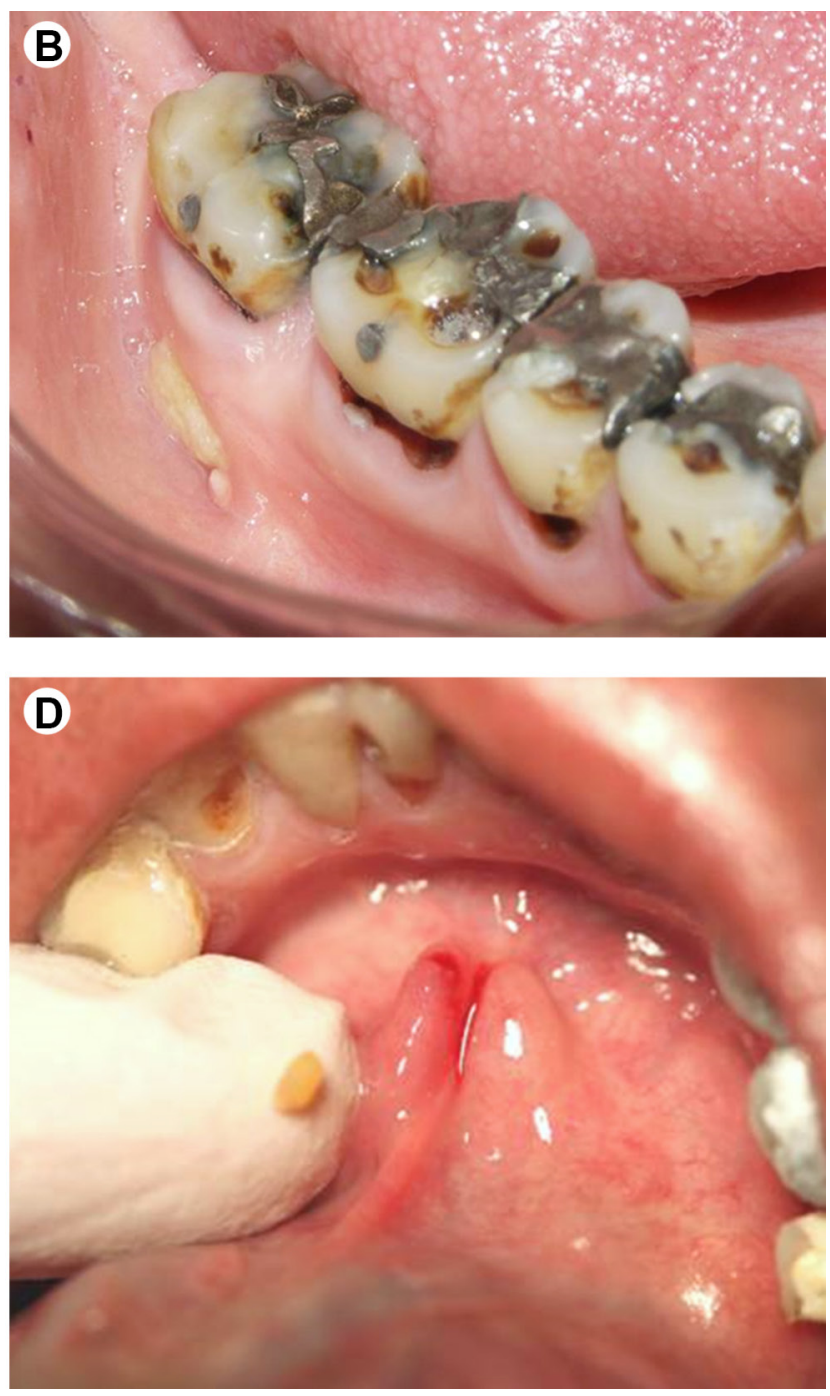

Figure 1. A,B: Generalized caries cavities, cracked restorations, fistula from dental abscess and (C,D) inflammation of the submandibular gland duct secondary to obstruction by calculus formation. 
full screening and no findings of lymphoma were found in other systems. No post-operative complications or relapse were observed after the surgical procedure and the patient remained well after 2-year follow-up.

A treatment plan was established based on the patient's oral conditions. Xerostomy was controlled with artificial saliva and gingival inflammation was treated with periodontal therapy, including professional removal of the dental biofilm and supra-gingival calculus. The dental caries and cracked restorations were removed, the teeth were restored with ionomer and amalgam to avoid dental biofilm formation. Dentoalveolar abscess was treated by root canal associated to antibiotic prophylaxis and therapy (amoxycillin $500 \mathrm{mg}, 4$ tablets $1 \mathrm{~h}$ before the procedure and 1 tablet every $8 \mathrm{~h}$ during 7 days after the procedure) to prevent apical bone necrosis, since she used risedronate and the partial dental loss was restored with fixed partial dentures. Three years after the second diagnosis of lymphoma, she experienced persistent diarrhea and weight loss secondary to SLE related gastrointestinal vasculitis, and she died 1 month later.

\section{Case 2}

A 37-year-old Brazilian woman was admitted to the Clinic for Special Needs Patients of the Dental School of Ribeirão Preto, USP - Universidade de São Paulo, presenting constant irritation of the eyes, enlargement of the parotid glands and dry mouth complaint for the last 3 years. The medical history was unremarkable. Upon physical examination was observed a bilateral erythematous eyelid, angular cheilitis and parotid gland enlargement, this latter more evident on the left side, imparting a facial
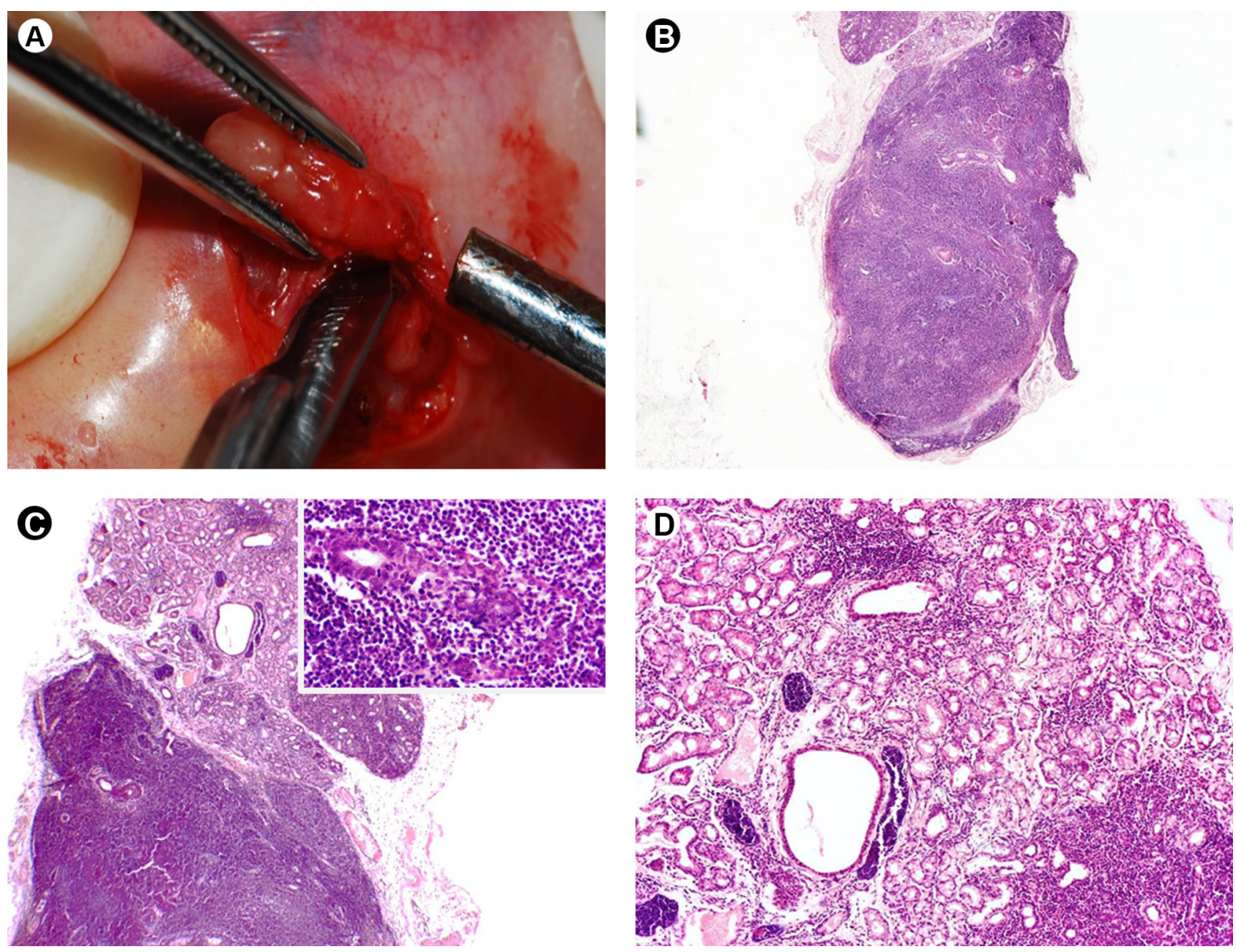

Figure 2. A: Surgical excision of the nodular lesion on the upper lip. B: Microscopic analysis showing a nodular proliferation of lymphoid cells involving the glandular parenchyma. C: Observe the interface with the residual minor salivary glands, highlighting the prominent infiltration of the glandular parenchyma. Notice the atypical lymphoid infiltrate surrounding the ductal epithelium (lymphoepithelial lesion) (inset). D: In high-power view, infiltration of the glandular parenchyma (bottom right area), intravascular location of lymphoid cells (bottom left area), and focal lymphocytic sialadenitis adjacent to normal-appearing mucous acini (upper area). Hematoxylin and eosin staining; original magnification: $\times 4(B), \times 10(C)$, and $\times 20(D)$. 
asymmetry (Fig. 4A). The oral physical examination revealed both atrophic and dry mucosa and the unstimulated whole salivary flow was $<1.5 \mathrm{~mL}$ in $15 \mathrm{~min}$.
The patient was referred to the Rheumathology Clinic of the Ribeirão Preto Medical School for screening of other alterations. Rose bengal and fluorescein score were
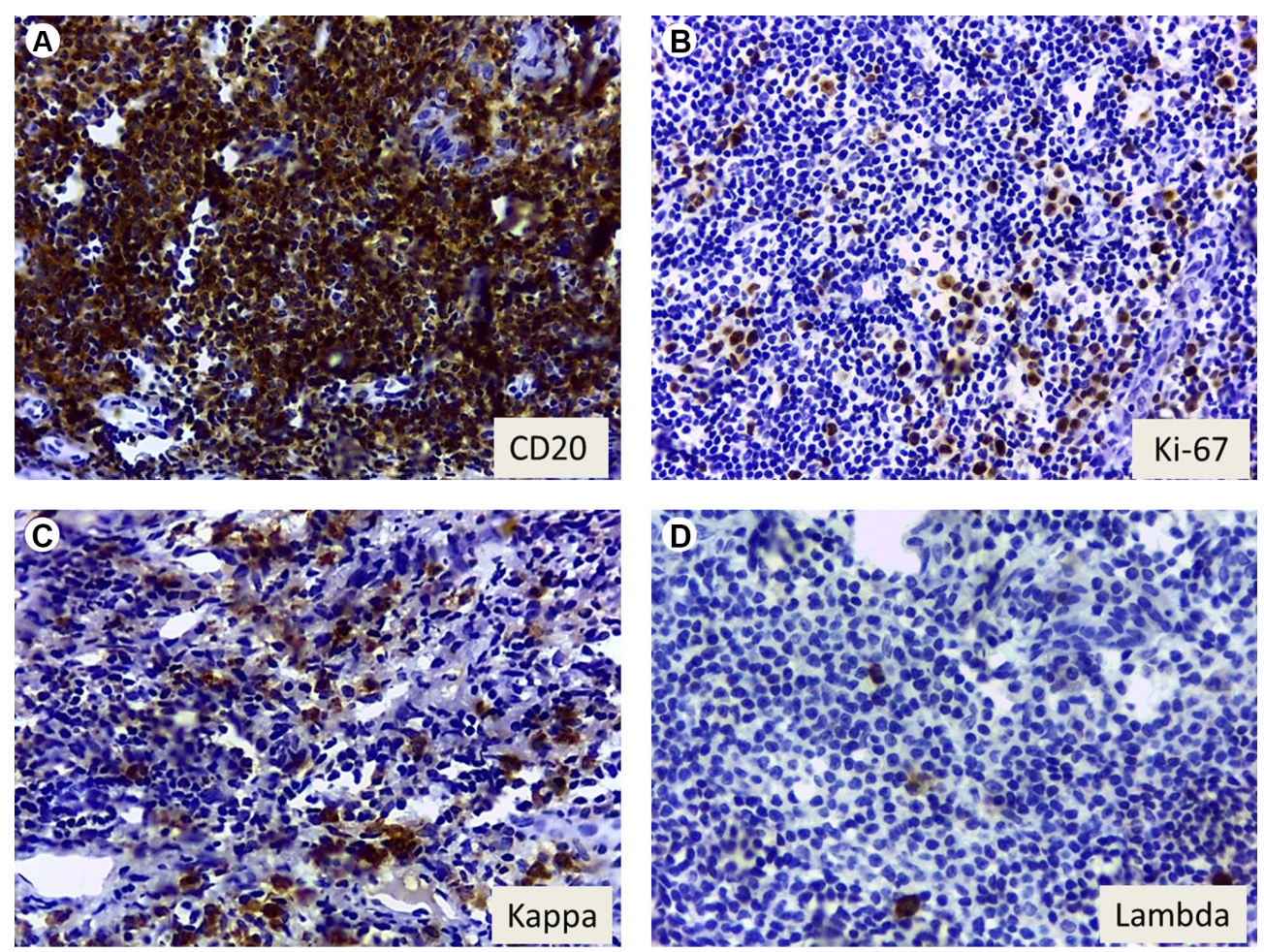

Figure 3. Immunohistochemical characterization of MALT lymphoma. A: There were numerous CD20 positive tumor cells, while CD3 positive cells were scarce (not shown). (b: The cell proliferation assessed by the Ki-67 index was $<15 \%$. C: The B-cell population did show kappa light chain restriction, confirming the diagnosis (D). Original magnification: $\times 40$ (A-D).
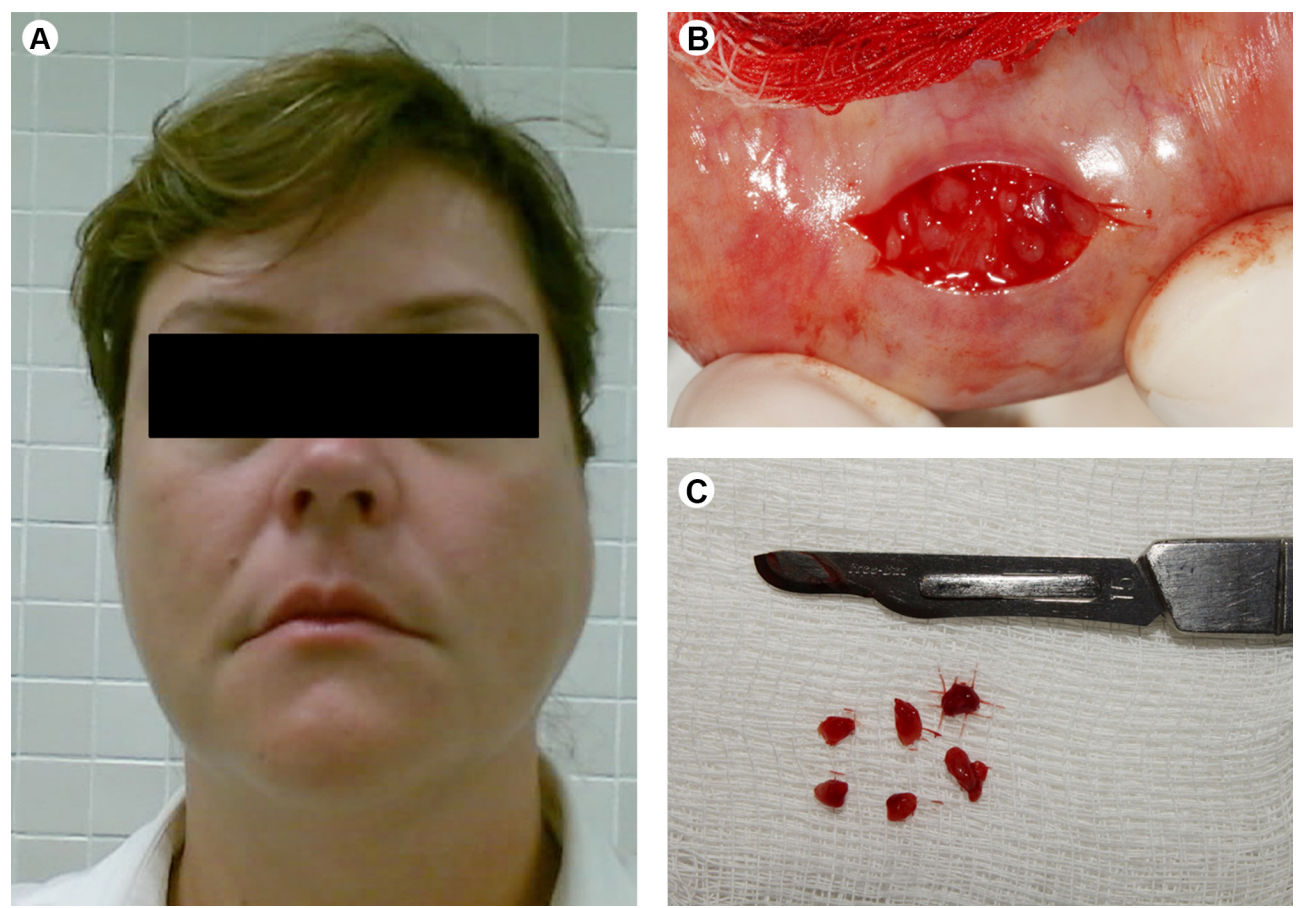

Figure 4. A: Enlargement of the parotid glands, which was more evident on the left side. B and C: Minor salivary gland biopsy. 
low, leading to a mild dry eye. Antinuclear autoantibody (ANA), SS-A, and SS-B autoantibody tests were positive and rheumatoid factor (RF) was negative. A minor labial salivary gland biopsy was taken (Figs. $4 \mathrm{~B}$ and $\mathrm{C}$ ), and the histopathological examination showed multifocal lymphocytic sialadenitis, being the focus score of $>1$ focus per $4 \mathrm{~mm}^{2}$ (Fig. 5) $(2,10,11)$. By IHC analysis, there were similar proportions of CD3- and CD20-positive cells, while CD138 evidenced scarce plasma cells at the periphery. There was no light chain restriction and the $\mathrm{Ki}-67$ index was $<5 \%$
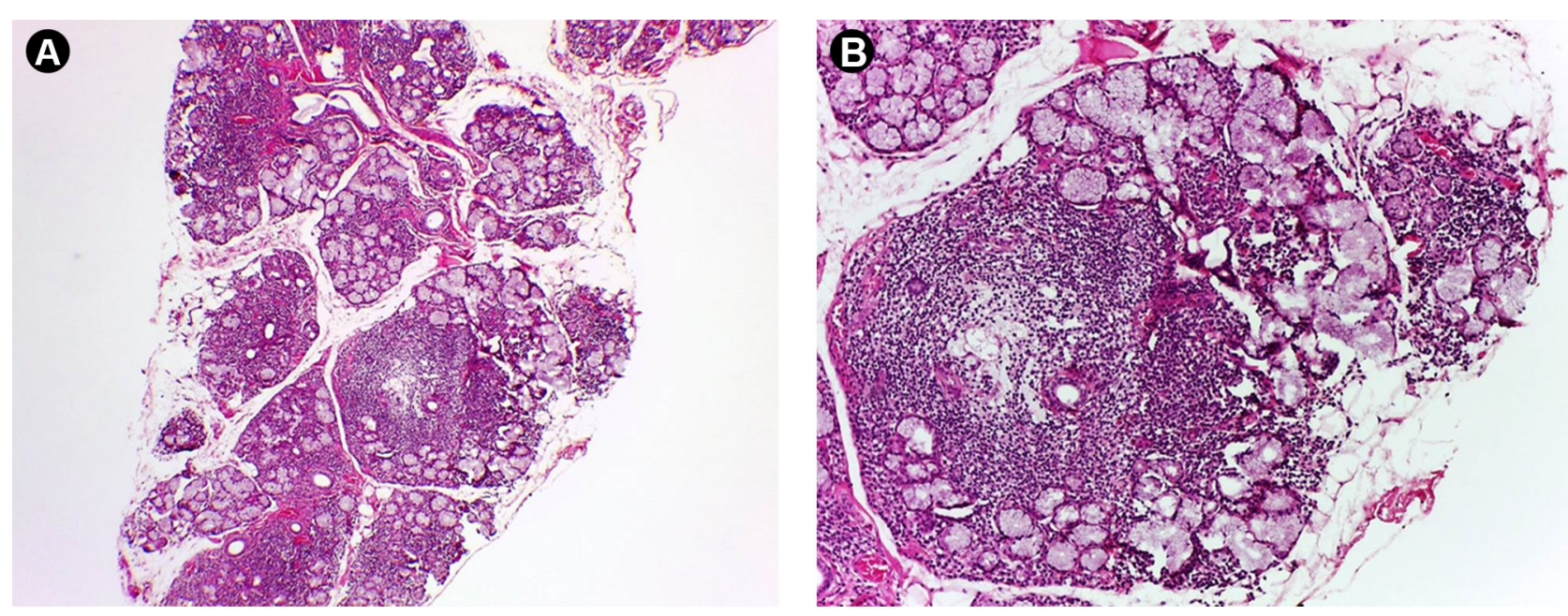

Figure 5. A and B: Chronic multifocal lymphocytic sialadenitis in the minor salivary glands. The focus score was $>1$. Hematoxylin and eosin staining; original magnification: $\times 4$ and $\times 20$.
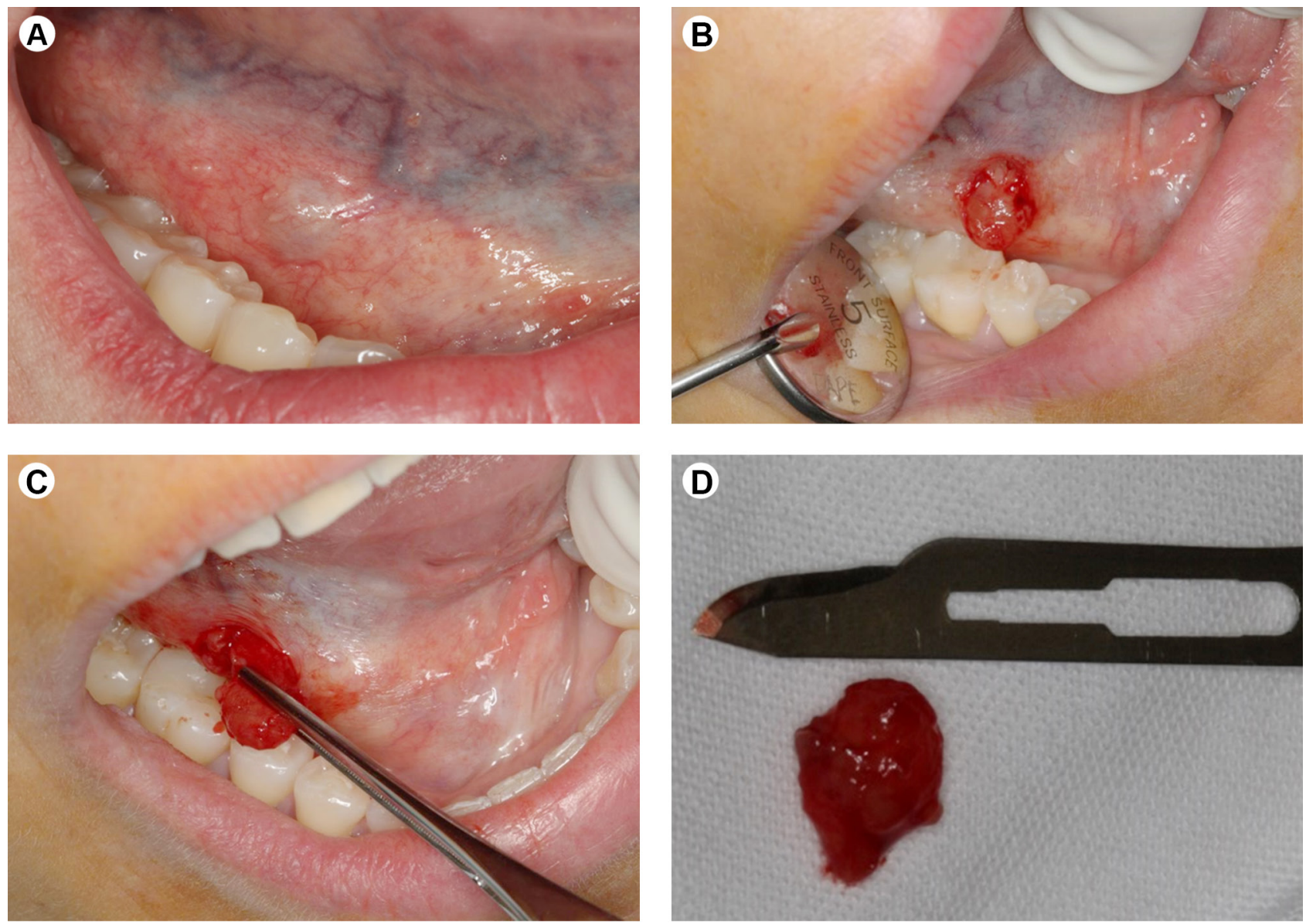

Figure 6. A-D: Surgical excision of the nodular lesion on the floor of the mouth. 

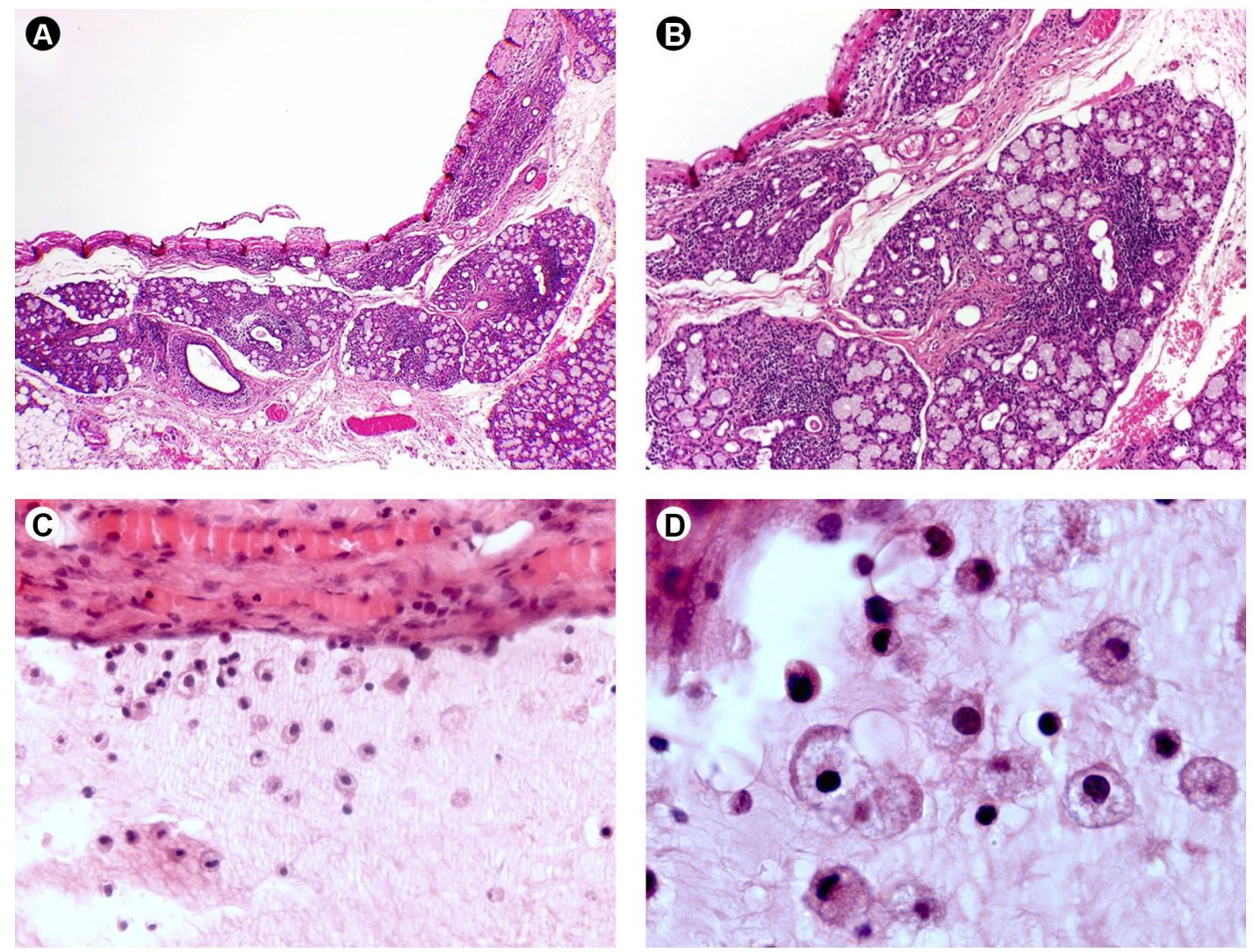

Figure 7. A: Pseudocystic cavity exhibiting sparse to absent mucoid material diagnosed as mucocele. B: Lymphocytic infiltration in the minor salivary glands surrounding the lesion, typically observed in Sjogren's syndrome. C,D: Wall of granulation tissue containing foamy macrophages. Hematoxylin and eosin staining; original magnification: $\times 4(\mathrm{~A}), \times 10$ (B), $\times 40$ (C) and $\times 100$ (D).

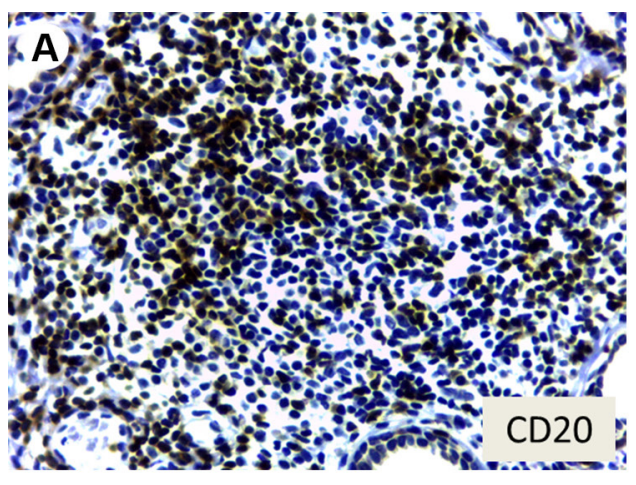

B. B. B

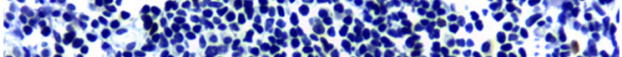

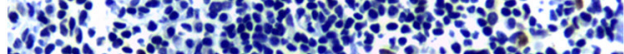
H.

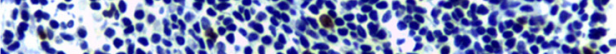

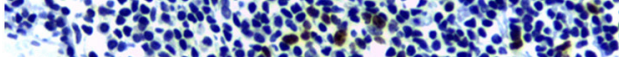

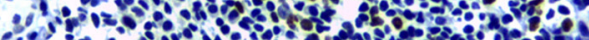

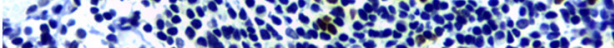

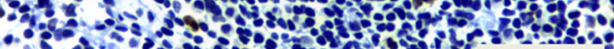

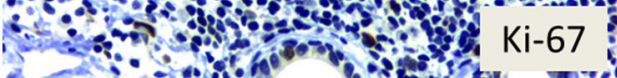
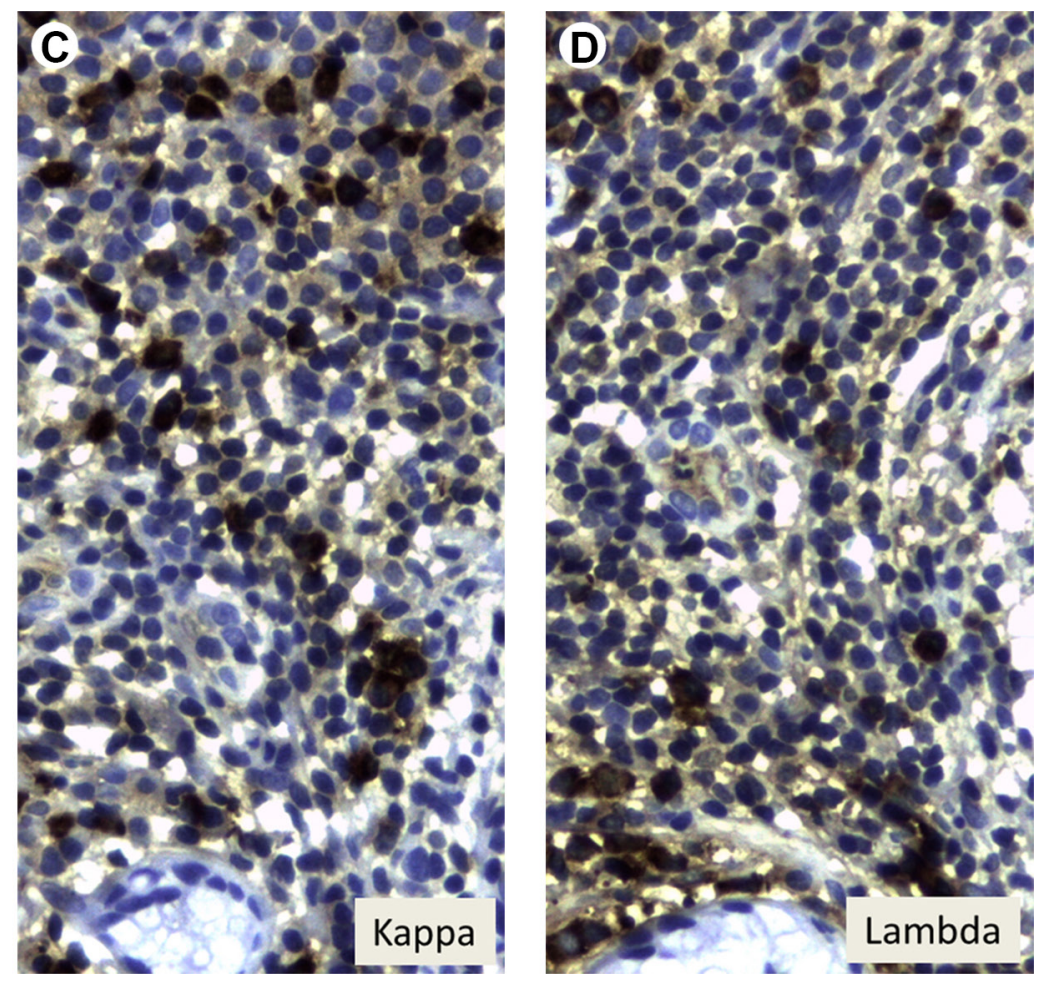

Figure 8. Immunohistochemical characterization of the multifocal lymphocytic sialadenitis. A: CD20 and CD3 (not shown) exhibiting similar immunoexpression. (B: The cell proliferation assessed by the Ki-67 index was <5\%. A,D: The B-cell population did not show light chain restriction. Original magnification: $\times 20(\mathrm{~A}, \mathrm{~B})$ : and $\times 40(\mathrm{C}, \mathrm{D})$. 
(Fig. 6). The diagnosis of pSS was established. The patient started a regimen of systemic prednisone at an initial daily dose of $60 \mathrm{mg}$, which was tapered gradually $(10 \mathrm{mg}$ ) each 7 days until stabilizing at daily $5 \mathrm{mg}$, methotrexate $15 \mathrm{mg}$ weekly, chloroquine diphosphate $250 \mathrm{mg}$ daily and artificial tears and saliva, improving all signs and symptoms presented at the beginning of her history. After around 1 year of the pSS diagnosis, she presented an asymptomatic nodular lesion on the floor of the mouth noticed by the patient (Fig. 7). As in Case 1, on the basis of clinical examination, the differential diagnosis of this lesion included a reactive or neoplastic lesion. The lesion was removed surgically and was diagnosed as oral mucocele after histopathological analysis (Fig. 8). The patient is currently receiving dental and medical follow-up and remains with no alterations.

\section{Discussion}

In this study were shown two cases of SS each one presenting an asymptomatic nodular lesion on the lip and floor of the mouth, which were diagnosed as a malignant and reactive lesion, respectively. Based on clinical examination, the potential differential diagnoses of both nodular lesions included reactive lesions such as mucocele and focal fibrous hyperplasia, as well as benign mesenchymal neoplasm including lipoma, neurofibroma, neurilemmoma and benign salivary gland neoplasm (12). Case 1 presented a compressive, encapsulated and asymptomatic lesion on the mucosa of the upper lip (Fig. 2), with a normal overlying mucosa, which was discovered during dental visit and the diagnosis was consistent with relapsed MALT lymphoma. Case 2 showed an asymptomatic swelling in the right floor of the mouth (Fig. 7), also with normal overlying mucosa, noticed by the patient and diagnosed as oral mucocele.

Twenty-four cases of oral primary MALT Iymphoma, excluding tonsil tissues, have been reported to date, $40 \%$ and $30 \%$ of them associated with autoimmune diseases and presenting regional nodal involvement, respectively $(13,14)$. MALT lymphomas follow a relatively indolent clinical course and remain localized to their primary extranodal site and the treatment is preferentially made with surgical resection and/or radiation. Similar to Case 1, recently a patient was reported with soft masses involving both lips, in which the differential diagnosis included inflammatory diseases, benign neoplasm or salivary gland tumor; however, the final diagnosis was MALT lymphoma (14). Dissemination of this neoplasm at multiple sites occurs in up to one-fourth of cases, with either synchronous or metachronous involvement of multiple mucosal sites or nonmucosal sites (13), like described in Case 1. In effect, the previous history of MALT lymphoma involving the parotid and submandibular glands in Case 1 was crucial.
Moreover, the morphological features and IHC analysis of the lip specimen were consistent with MALT Iymphoma (13). Thus, oral nodular lesions in SS patients with previous history of malignant lymphoma should raise the suspicion of relapsed lymphoma. Interestingly, there is one lip MALT lymphoma case affecting a SS patient which was diagnosed evaluating a minor labial salivary gland biopsy at the 2-year follow-up. In this case, the patient did not show clinical alterations (6). This emphasizes the need of periodic local and systemic evaluation in SS patients, including image study like computerized tomography or magnetic resonance imaging if required.

Oral mucocele is a common reactive lesion involving the minor salivary glands, which histopathologically exhibits mucus extravasation surrounded by a wall of granulation tissue containing foamy macrophages (15). In Case 2 , the nodular lesion on the floor of the mouth showed microscopically a central empty cavity and scarce foamy macrophages on the wall of the granulation tissue. It is reasonable to suggest that the underlying disease (pSS) has influenced these morphological features. The report of two giant mucoceles on the floor of the mouth in elderly female patients with SS suggests that the pathogenesis of mucocele in this autoimmune disorder must be better understood (8). Probably, the lymphocytic infiltrate may cause the destruction of salivary gland ducts resulting in the development of mucocele (8).

This article demonstrated how dentists may contribute with the diagnosis and management of SS and its complications since the oral manifestations can be specific findings. In the Case 1 reported in this study, the patient was referred to the service with the diagnosis established by a medical team, and the dental staff was responsible for the effective oral/dental treatment, including xerostomy control, periodontal diseases, surgery, caries, root canal and fixed partial dentures. Additionally, the dental staff also contributed with the diagnosis of relapsed MALT Iymphoma. In Case 2, the dentist was responsible for the SS diagnosis from the signs and symptoms presented by the patient, leading to minor salivary gland biopsy and the early detection of disease and little commitment, both oral and systemic. Both patients were under regular dental visit to maintain the oral health. Besides that contribution, Case 1 gave the dental staff an opportunity to deal with a patient with a complex systemic condition, treated by multiple drugs, including risedronate, prednisone, carbamazepine, and acetylsalicylic acid, who unfortunately died due to gastrointestinal complications of SLE.. Additional care was required for the safety of dental procedure: root canal was associated to antibiotic prophylaxis and therapy to prevent osteonecrosis of apical bone, and all oral surgeries were followed using fibrin sponges and occlusive primary 
suture since she used acetylsalicylic acid (an antiplatelet agent). Finally, case reports describing MALT lymphoma and mucocele in SS are scarce in the literature; and reports like the current paper may help dentists and medical staff facing this disease.

\section{Resumo}

A sindrome de Sjögren (SS) é uma doença autoimune crônica sistêmica que afeta as glândulas lacrimal e salivar. A SS pode se manifestar como SS primária (SSp) ou SS secundária (SSs), a última ocorrendo em conjunto com outra desordem autoimune. Em ambos os casos, os olhos secos e a boca seca afetam a qualidade de vida do paciente. As complicações tardias podem incluir cegueira, destruição dos tecidos dentários, candidiase oral e linfoma. Este artigo relata dois casos de SS, cada um apresentando lesão nodular oral incomum diagnosticada como linfoma MALT reincidente e mucocele. A importância do diagnóstico, tratamento e manejo das lesões orais por um cirurgião-dentista durante 0 atendimento de pacientes com SS é enfatizada, pois as manifestações orais da SS podem comprometer a qualidade de vida do paciente.

\section{Acknowledgements}

The authors would like to thank Dr. Rosemeire de Lordo Franco Gobbo and Dr. Jessica Luana dos Santos for their clinical and histological assistance, respectively.

\section{References}

1. Stewart CM, Berg KM, Cha S, Reeves WH. Salivary dysfunction and quality of life in Sjogren syndrome: a critical oral-systemic connection. J Am Dent Assoc 2008;139:291-299; quiz 358-299.

2. Vitali $C$, Bombardieri $S$, Jonsson R, Moutsopoulos HM, Alexander EL, Carsons SE, et al.. Classification criteria for Sjogren's syndrome: a revised version of the European criteria proposed by the AmericanEuropean Consensus Group. Ann Rheum Dis 2002;61:554-558.

3. Delaleu N, Jonsson R, Koller MM. Sjogren's syndrome. Eur J Oral Sci 2005;113:101-113.
4. Iacopino AM. Sjogren syndrome: reduced quality of life as an oralsystemic consequence. J Can Dent Assoc 2010;76:a98.

5. Alves MB, Motta AC, Messina WC, Migliari DA. Saliva substitute in xerostomic patients with primary Sjogren's syndrome: a single-blind trial. Quintessence Int 2004;35:392-396.

6. Keszler A, Adler LI, Gandolfo MS, Masquijo Bisio PA, Smith AC, Vollenweider CF, et al.. MALT lymphoma in labial salivary gland biopsy from Sjogren syndrome: importance of follow-up in early detection. Oral Surg Oral Med Oral Pathol Oral Radiol 2013;115:e28-e33.

7. Speight PM, Jordan R, Colloby $\mathrm{P}, \mathrm{Nandha} H$, Pringle JH. Early detection of lymphomas in Sjogren's syndrome by in situ hybridisation for kappa and lambda light chain mRNA in labial salivary glands. European Journal of Cancer Part B, Oral oncology 1994;30B:244-247.

8. Katayama I, Yamazaki S, Nishioka K. Giant mucocele of oral cavity as a mucocutaneous manifestation of Sjogren syndrome. J Dermatol 1993;20:238-241.

9. Napenas JJ, Rouleau TS. Oral complications of Sjogren's syndrome. Oral and Maxillofacial Surgery Clinics of North America 2014;26:55-62.

10. Chisholm DM, Mason DK. Labial salivary gland biopsy in Sjogren's disease. J Clin Pathol 1968;21:656-660.

11. Daniels TE, Whitcher JP. Association of patterns of labial salivary gland inflammation with keratoconjunctivitis sicca. Analysis of 618 patients with suspected Sjogren's syndrome. Arthritis Rheum 1994;37:869-877.

12. Conceicao JG, Gurgel CA, Ramos EA, De Aquino Xavier FC, Schlaepfer-Sales CB, Cangussu MC, et al.. Oral mucoceles: a clinical, histopathological and immunohistochemical study. Acta Histochem 2014;116:40-47.

13. Carlos Bregni R, Nuyens M, Vassallo J, Soares FA, Romanach MJ, Leon

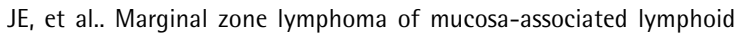
tissue with prominent plasma cell differentiation affecting the palatine tonsil: histopathological and immunohistochemical analysis. Oral Surg Oral Med Oral Pathol Oral Radiol 2012;113:526-532.

14. Kawasaki G, Yanamoto S, Kawano T, Yoshitomi I, Yamada S, Rokutanda $\mathrm{S}$, et al.. Soft masses occurring simultaneously in the upper and lower lips. Oral Surg Oral Med Oral Pathol Oral Radiol 2014;117:147-152.

15. Pina AR, Almeida LY, Andrade BA, Leon JE. Clear cell change in a lower lip mucocele. J Oral Maxillofac Pathol 2013;17:318.

Received May 2, 2016 Accepted February 14, 2017 